\title{
Using the Triptych model for future burden sharing - a case study for Flanders
}

\author{
K. Claes \& I. Moorkens \\ VITO - Flemish Institute for Technological Research, Belgium
}

\begin{abstract}
To prevent extreme damage caused by climate change, the EU put forward a target of a maximum temperature rise of $2^{\circ} \mathrm{C}$. As a consequence, the global greenhouse gas emissions should be cut by 15 to $50 \%$ by 2050 . However, eventually every Member State has to be given a specific emission reduction target. Since carbon emissions have a cost, a protectionist reflex in burden sharing negotiations can be expected. Therefore, as with Triptych in 1997, a scientific model-based proposition will probably be generated, prior to political discussions. To be acceptable, this model must be transparent. A crucial aspect is how to deal with local conditions: Are degree-days to be incorporated? Should countries be compensated for phasing out nuclear energy?

A case study was carried out applying the Triptych model to the situation in Flanders. The Triptych approach is a sector specific approach distinguishing three groups of economic sectors: the energy-intensive industry, the powerproducing industry and the domestic sectors. Two variants of the model were used: an improved version of the original European model and a global version. In the former, specific $\mathrm{CO}_{2}$ emissions from the energy-intensive industry are expected to be reduced by $1.5 \%$ per year. In the power-producing sector the energy efficiency is improved by $1 \%$ each year. The domestic sectors take into account convergence of 1990 per capita emission levels to equal per capita allowances in 2030. In the Global Triptych approach, convergence is applied to all three sectors. The outcome of the model was compared to projected energy use in Flanders until 2020. The comparison shows a gap between the results of the Triptych exercise and what may be expected in a business-as-usual scenario. Keywords: climate change, burden sharing, $\mathrm{CO}_{2}$ emissions, Triptych model, emission projections.
\end{abstract}




\section{Introduction}

In the combat against Climate Change, a strong reduction of global greenhouse gas emissions is required. In international negotiations, for instance under the United Nations Framework Convention on Climate Change, the European Union is one of the key players. The EU takes the lead whenever new emission reduction targets or a new climate regime have to be discussed. The position of the EU at the international discussions is prepared thoroughly inside the Union. It is the result of a process of discussion between the member states.

When preparing a negotiating position for COP 3 in Kyoto, the EU had differentiated an overall emission reduction target of $-9 \%$ between its member states. The negotiating position of the EU at COP 3 was $-15 \%$. The sum of individual allowances resulted in an EU target of only $-9 \%$. This 'burden sharing', in which every country got an individual emission reduction target, was based on the Triptych model, developed at the University of Utrecht. This model based approach was proposed by the Dutch Presidency in 1997. Of course there was also a great deal of political influence on the eventual burden sharing, but the model had given a start to negotiations.

The result of negotiations at Kyoto was a reduction target of $-8 \%$ for the EU. So afterwards, the individual member states were given a new national target.

\section{Scope}

When the EU will take on a new emission reduction target in the future, a national target will be given to Belgium. Within Belgium, this target will be divided between the regions, which are responsible for implementing climate policy. To be prepared for both external and internal burden sharing negotiations, the Flemish government wanted to know the possible impact of the use of the Triptych model on Flanders. We investigated this impact using an improved version of the Triptych model, elaborated by Groenenberg [1]. Besides the improved Triptych model, we also used the Global Triptych approach, which was also elaborated by Groenenberg [1].

In this paper we present the results of the application of both Triptych versions to Flanders.

In addition, we compare the results to another research project by Duerinck et al. $[2,3]$ in which projected emissions for Flanders in 2020 were calculated in a 'business as usual' scenario. This is a scenario that includes to some extent climate policy measures.

\section{Description of the Triptych model}

The Triptych approach is a method to share emission allowances among a group of countries, taking into account main differences in national circumstances between countries that are relevant to emissions and emission reduction potentials. The Triptych approach as such does not define, which countries should participate. 
In the Triptych approach, three broad sources of emissions were distinguished: the power sector, the group of energy-intensive industries and the 'domestic' sectors. The selection of these categories was based on a number of differences in national circumstances raised in the negotiations: differences in standard of living, in fuel mix for the generation of electricity, in economic structure and the competitiveness of internationally-oriented industries. For each of the categories a reasonable amount of emission allowances is calculated by applying a defined set of rules to all countries. The allowances for each category are added up to a national target for each country. Only one national target per country is proposed, no sectoral targets, to allow countries the flexibility to pursue any cost-effective emission reduction strategy.

This version of the Triptych model only looks at $\mathrm{CO}_{2}$ emissions. Other greenhouse gases were not considered.

Groenenberg looked at two versions of the Triptych. First, she improved the existing model that was used during the EU burden sharing procedure in 1997, further referred to as European Triptych. Then she developed a Global Triptych model that can be used for a global differentiation of commitments.

\subsection{Improved European Triptych model}

The power sector is considered separately because specific $\mathrm{CO}_{2}$ emissions from power production vary to a large extent, due to large differences in the share of nuclear power and renewable energy sources and in the fuel mix in fossil fuelfired power plants. The potential for cutting greenhouse gases from this sector differs accordingly. Therefore fuel mix in power generation is an important national circumstance to account for in a differentiation of commitments. The criteria and assumptions for this sector are the following:

- The growth rate in power production equals the economic growth minus an annual reduction of $1 \%$ to correct for the reduced demand due to autonomous efficiency improvements. The annual economic growth rate was taken from the World Energy Council and the International Institute for Applied System Analysis. The number for Western Europe is $1.9 \%$. So the annual growth rate comes down to $1.019 * 0.99=0.88 \%$. This means that in 25 years (1990-2015) power demand will grow by $25 \%$

- The electricity output generated with solid and liquid fossil fuels is reduced with $30 \%$ each.

- $\quad$ The 2015 share of nuclear power capacity equals the share in 1990.

- Renewable energy sources have an additional share of $15 \%$ on top of their 1990 output.

- Combined heat and power produces an additional $15 \%$ of the electricity in 2015 .

- The remaining electricity is produced with natural gas.

- Average generating efficiencies for solid, liquid and gaseous fuels converge linearly to $60 \%$ for natural gas and $45 \%$ for solids and liquids in 2030 .

Application of these assumptions to Flanders, lowers the overall emission factor by $22 \%$ between 1990 and 2015 . 
The internationally oriented energy-intensive industry, also indicated as heavy industry, has relatively high $\mathrm{CO}_{2}$ emissions per unit of production. Consequently, countries that rely to a large extent on this sector have higher emissions than countries that rely more on services, light industry or agriculture. The international character of this sector means that countries lacking sizeable heavy industries import goods from heavy industry in other countries and thus profit from other countries' efforts in this sector. Countries should not necessarily be penalised for an energy-intensive industry as they supply goods consumed by other countries. The energy-intensive industry comprises following sectors: iron and steel, chemicals, pulp and paper, non-metallic minerals, nonferrous metals and the energy transformation sector.

Criteria and assumptions:

- Growth rates for physical production (OECD countries): Iron and Steel: 0.7\%; Chemicals: 1.8\%; Petroleum Refineries: 1.0\%; Pulp \& Paper: $1.5 \%$; Cement: $1.0 \%$

Growth rates for the entire non-metallic minerals sector are assumed to be equal to those in the cement sector. Growth rates in the non-ferrous metals industry are assumed equal to those in the iron and steel industry.

- Specific carbon dioxide emissions are reduced by $1.5 \%$ per year. Differences in energy efficiency are not taken into account.

The domestic sectors comprise various sectors: the residential sector, the commercial sector, transportation, light industry and agriculture. Emissions in these sectors are correlated with population size. Following criteria and assumptions were used:

- Population growth in Flanders is forecasted at $+7 \%$ between 1990 and 2020 .

- 1990 per capita emission levels for the various countries converge to equal per capita allowances in 2030 . In this way it takes into account differences in the standard of living assumed to be reduced in the future

- The convergence level was set on 3.44 ton per capita. Philipsen et al. [4].

\subsection{Global Triptych}

Like European Triptych, Global Triptych is a sector- and technology based approach. Using bottom-up information, the equity principle from the Climate Convention and sustainable development can be observed in the calculations. Quantitative emission limitations are calculated starting from bottom-up information on long-term reduction opportunities. Improvement in energy efficiency can be achieved by technology transfer throughout the world. Global Triptych is based on a moderate increase in activity for all sectors and on advanced technological possibilities. Convergence trajectories are prescribed in each of the three energy-consuming sectors. Worldwide convergence should be realised in the energy-efficiency of heavy industry, in the carbon intensity of power generation and in the emissions per capita in the domestic sectors by the year 2050. The reference year is 1995 . 
In the heavy industry Global Triptych uses a growth factor of 1.2 between 1995 and 2020. This corresponds to an annual growth of $0.7 \%$. Besides this rise in physical production, an important efficiency improvement is expected. This is expressed with an index where 1 corresponds to the energy efficiency of the best available technologies in 1990. Energy efficiency is expected to converge globally to an energy-efficiency index of 0.67 in 2050. In 1990 Western Europe reached a score of 1.2. De Beer [5].

For the domestic sectors Global Triptych requires a convergence level of 2 tons of $\mathrm{CO}_{2}$ per capita in 2050. In the reference year 1995 the emissions in Flanders were over 6 ton per capita. Renewable energy sources are expected to reach a share of $40 \%$ in the global fuel mix by 2050 .

The emissions in the power sector are determined by power demand from the other two sectors. Power demand from the heavy industry goes down by $8 \%$ between 1995 and 2020. Power demand from domestic sectors falls by $27 \%$ in the same period. This results in an overall decrease of power demand by $20 \%$. Next to dropping power demand, the carbon intensity of power production has a great influence on emissions. Global triptych assumes a global convergence to $200 \mathrm{~g} / \mathrm{kWh}$ in 2050. Johansson et al. [6]. In the reference year 1995, the carbon intensity of power production in Flanders was about $400 \mathrm{~g} / \mathrm{kWh}$. This evolution accounts for a drop in carbon intensity with 23\% between 1995 and 2020.

The combination of reduced power demand and a lower carbon intensity results in a 38\% decrease of emissions between 1990 and 2020.

\section{Projected emissions in a business as usual scenario}

In a parallel investigation, independent from the Triptych exercise, emission projections for 2020 were made on a sectoral base. This study is further referred to as 'business as usual' or BAU $[2,3]$. The emission projections were developed using a bottom-up approach. Overall energy use was calculated and forecasted starting from the energy demand from separate sections in society (industry, households, power production, ...). In this context, business as usual means that to some extent existing policy measures were taken into account. Furthermore, some important assumptions were made in the BAU project:

Concerning the implementation of new technologies, a certain evolution is assumed, not a revolution.

The starting point of BAU calculations is 2000. The sectoral classification differs from the one in Triptych. Therefore, to make a comparison, the BAU projections had to be regrouped according to the three Triptych sectors.

\section{Results}

\subsection{European Triptych}

1990 was chosen as the starting point for our calculations. Data for this reference year were taken from the Energy Balance of Flanders by Aernouts and Jespers [7]. The Triptych exercise made by Groenenberg [1] went up to 2015. 
Since the next emission reduction target will probably be set for 2020 , we extended the calculations until 2020.

The following results were obtained:

Table 1: $\quad$ Projected emissions - European Triptych - BAU 1990-2020.

\begin{tabular}{|l|c|c|c|c|c|}
\hline [kton] & $\mathbf{1 9 9 0}$ & $\mathbf{2 0 1 5}$ & $\mathbf{2 0 2 0}$ & $\begin{array}{c}\mathbf{2 0 1 5} / \\
\mathbf{1 9 9 0}\end{array}$ & $\begin{array}{c}\mathbf{2 0 2 0} / \\
\mathbf{1 9 9 0}\end{array}$ \\
\hline Power & 17782 & 17358 & 17274 & $-2.4 \%$ & $-2.9 \%$ \\
\hline Energy intensive industry & 16435 & 15447 & 15276 & $-6.0 \%$ & $-7.1 \%$ \\
\hline Domestic sectors & 32232 & 26014 & 24467 & $-19.3 \%$ & $-24.1 \%$ \\
\hline Total & 66449 & 58819 & 57016 & $-11.5 \%$ & $-14.2 \%$ \\
\hline
\end{tabular}

When we compare the outcome in 2020 with the reference year 1990, the total emission reduction we are looking at is $-14 \%$. The biggest cut has to be made in the domestic sectors: $-24 \%$. The energy sector only has to reduce its emissions by $3 \%$. Heavy industry is somewhere in between with a $7 \%$ cut.

The outcome for the power sector is the result of several evolutions. The expected economic growth in this period amounts to $76 \%(+1.9 \%$ per year), but thanks to the autonomous efficiency improvement of $1 \%$ per year, the effect of economic growth on emissions is limited to $+30 \%$. Taking into account a lower carbon intensity, emissions show a net drop of $3 \%$.

Emissions of the energy-intensive industry fall by 7\% between 1990 and 2020. But there are important differences between sub sectors. The expected economical growth lies between $0.7 \%$ a year for steel and non-ferrous metals and $1.8 \%$ for chemicals. The assumed efficiency improvement is $1.5 \%$ for all sectors. The net yearly reduction in emissions is the combined result of both economical growth and efficiency improvement. For some sectors there is a rise in emissions, in other sectors emissions fall.

The evolution of emissions in the domestic sectors depends on population growth and the assigned emission per capita. Against a limited rise in population $(+7 \%)$ between 1990 and 2020, a strong decline in emissions per capita $(-29 \%)$ is put forward. The net result is a decline in $\mathrm{CO}_{2}$ emissions of $24 \%$.

\subsection{Global Triptych}

When we look at the period 1990-2020, the resulting emission reduction is slightly larger then in the European Triptych approach. Especially the power sector shows a large difference.

In the power-producing sector the calculated emission reduction amounts to $38 \%$ between 1990 and 2020. This is a much larger emission reduction then calculated with the European Triptych. Both models assume a heavy decrease in carbon intensity, but there is a big difference in power demand. According to European Triptych power demand will rise whereas Global Triptych expects a reduced demand from the other two sectors. The latter is the result of ambitious convergence paths for both energy efficiency in the heavy industry and 
emissions per capita in the domestic sectors. This is part of the specific global approach in which long-term sustainability targets are pursued.

Table 2: $\quad$ Projected emissions - Global Triptych - BAU 1990-2020.

\begin{tabular}{|l|c|c|c|c|l|}
\hline [kton] & $\mathbf{1 9 9 0}$ & $\mathbf{2 0 1 5}$ & $\mathbf{2 0 2 0}$ & $\begin{array}{c}\mathbf{2 0 1 5} / \\
\mathbf{1 9 9 0}\end{array}$ & $\begin{array}{c}\mathbf{2 0 2 0} / \\
\mathbf{1 9 9 0}\end{array}$ \\
\hline Power sector & 17782 & 12145 & 10972 & $-31.7 \%$ & $-38.3 \%$ \\
\hline Energy-intensive industry & 16435 & 15201 & 14952 & $-7.5 \%$ & $-9.0 \%$ \\
\hline Domestic sectors & 32232 & 28133 & 25982 & $-12.7 \%$ & $-19.4 \%$ \\
\hline Total & 66449 & 55478 & 51906 & $-16.5 \%$ & $-21.9 \%$ \\
\hline
\end{tabular}

The energy-intensive industry shows a reduction of $9 \%$, which is not far from the result of European Triptych (-7\%). European Triptych has the biggest efficiency improvement, but in Global Triptych a lower growth rate is assumed.

In the domestic sectors emission reduction is slightly less then with European Triptych: $-19 \%$ instead of $-24 \%$. The reason is that the slope of the convergence path of the European model is steeper.

\section{Comparison with emission projections in a business as usual scenario}

In the BAU research project a climate correction was made using degree-days. In order to compare the Triptych results with the BAU emission projections, the same climate correction was made for Triptych. The BAU results were regrouped to be comparable to the Triptych sectors.

Following table shows the comparable results for European Triptych, Global Triptych and BAU.

Table 3: $\quad$ Projected change in emissions 1990-2020.

\begin{tabular}{|l|l|c|c|}
\hline \multirow{2}{*}{ Model } & \multirow{2}{*}{ Sector } & \multicolumn{2}{|c|}{$\mathbf{2 0 2 0} / \mathbf{1 9 9 0}$} \\
\cline { 2 - 4 } & & {$[$ kton] } & {$[\%]$} \\
\hline \multirow{2}{*}{$\begin{array}{l}\text { European } \\
\text { Triptych } \\
\text { after climate } \\
\text { correction) }\end{array}$} & Power sector & -392 & -2.2 \\
\cline { 2 - 4 } & Energy-intensive industry & -1160 & -7.1 \\
\cline { 2 - 4 } $\begin{array}{l}\text { Global } \\
\text { Triptych } \\
\text { (after climate } \\
\text { correction) }\end{array}$ & Domestic sectors & -6251 & -19.4 \\
\cline { 2 - 4 } & Potal & -7803 & -11.7 \\
\cline { 2 - 4 } & Energy-intensive industry & -6790 & -38.2 \\
\cline { 2 - 4 } & Domestic sectors & -1483 & -9.0 \\
\cline { 2 - 4 } $\begin{array}{l}\text { BAU- } \\
\text { prognoses }\end{array}$ & Total & -5810 & -18.0 \\
\cline { 2 - 4 } & Eower sector & -14083 & -21.2 \\
\cline { 2 - 4 } & Domergy-intensive industry & 817 & 14.2 \\
\cline { 2 - 4 } & Total & 5977 & 18.0 \\
\hline
\end{tabular}

There are huge differences between the projected emissions and the Triptych results. In a business as usual scenario a $14 \%$ increase in emissions is expected. Triptych shows a decrease of $-12 \%$ to $-21 \%$. 
There are several possible reasons for these differences. First of all, both inquiries use different methodologies with their own specific objectives. Different starting points also play an important role. By starting in 1990 or 1995 , Triptych does not take into account the whole historical rise in emissions between 1990 and 2000. Another obstacle that complicates the comparison of the two studies is the way Combined Heat and Power is dealt with. In the BAU projections all emissions of a new CHP plant are allocated to the energy sector. Hence, more CHP means more emissions in the energy sector and less in heavy industry.

Part of the differences can be attributed to assumptions on economic growth and efficiency improvement.

In the heavy industry a bigger growth in physical production is assumed by Triptych than in BAU. However, because of the strong energy efficiency improvement emission reduction is bigger in Triptych than in BAU. This results in a $5 \%$ rise in emissions according to BAU, versus a decline of $-7 \%$ to $-9 \%$ according to Triptych.

The power sector also shows big differences. There is a predicted rise of $14 \%$ versus a $2 \%$ decline according to European Triptych. Global Triptych even results in a $-38 \%$ decrease.

European Triptych assumes a rising power demand, but emissions go down thanks to a dropping carbon intensity. In Global Triptych both demand and carbon intensity go down. In the BAU projections rising emissions are partly due to the specific allocation method for CHP.

In the domestic sectors, emissions are projected to grow by almost $19 \%$ compared to a -18 to $-19 \%$ decline when using Triptych. The latter is caused by converging per capita emissions against a modest population growth.

\section{Conclusions}

Models like Triptych can be a helpful instrument when negotiating a burden sharing agreement between countries. Yet, it is still a theoretical exercise that differs from the existing situation in the countries concerned. When applying the Triptych method to Flanders and comparing the results to more elaborated emission projections, we found a large discrepancy. To be of practical use, as much national circumstances as possible should be incorporated in the Triptych approach.

In order to make the necessary cuts in global greenhouse gas emissions more countries should take part in an international climate regime. This means that the Triptych model has to be expanded to a more global scale. As a consequence it will be more difficult to go into detail when looking at data like economic growth, energy mix, energy efficiency improvement rates, structure of the economy etcetera. Hence, the need for the incorporation of national circumstances in the model seems to be opposite to the need to establish a climate regime for a larger group of countries. 
To resolve this paradox, capacity building in developing countries should be given more attention and support. Improving the quality of key data can facilitate the use of the Triptych model, taking into account to some extent national circumstances.

\section{References}

[1] Groenenberg, H., Development and Convergence, a bottom-up analysis for the differentiation of future commitments under the Climate Convention Doctoraal Proefschrift, Utrecht University, ISBN 90-393-3189-8, 2002

[2] Duerinck, J., Briffaerts, K., Vercalsteren, A., Nijs, W., Cornelis, E., De Vlieger, I, Energie- en broeikasgasscenario's voor het Vlaamse gewest: Business as usual scenario tot en met 2030, VITO rapport, 2005/IMS/R/209, 2005

[3] Duerinck, J., Briffaerts, K., Vercalsteren, A., Nijs, W., Cornelis, E., De Vlieger, I, Energie- en broeikasgasscenario's voor het Vlaamse gewest: Referentiescenario tot en met 2012, VITO rapport, 2005/IMS/R/210, 2005

[4] Phylipsen, G.J.M., Bode, J.W., Blok, K., Merkus, H. and Metz, B., A Triptych sectoral approach to burden sharing differentiation; GHG emissions in the European bubble, Energy policy, 26, pp. 929-943, 1998

[5] De Beer, J., Potential for industrial energy efficiency improvement in the long term. Thesis, Utrecht University, 1998

[6] Johansson, T.B. et al., Renewable fuels and electricity for a growing world economy: defining and achieving the potential, Renewable Energy; Sources for fuels and electricity, Island Press, Washington DC, 1993

[7] Aernouts, K., en Jespers K., Energiebalans Vlaanderen 2002, VITO rapport, 2004 